\title{
Adapting the dynamic LakeMab model to simulate seasonal variations of phosphorus concentration in reservoirs: a case study of Lake Bultière (France)
}

\author{
Vincent Roubeix ${ }^{1,2}$ (D) $\cdot$ Camille Minaudo ${ }^{3} \cdot$ Jordi Prats $^{1,2,4} \cdot$ Nathalie Reynaud $^{1,2} \cdot$ Qian Zhang $^{5} \cdot$ Florentina Moatar $^{6}$. \\ Pierre-Alain Danis ${ }^{1,7}$
}

Received: 14 September 2019 / Accepted: 26 December 2019 / Published online: 14 January 2020

(c) The Japanese Society of Limnology 2020

\begin{abstract}
Controlling phosphorus is fundamental to limit the risk of eutrophication of continental aquatic ecosystems. Integrated modelling of its concentration in the aquatic continuum requires specific tools for water bodies. However, although simple static empirical models and complex biogeochemical models are numerous, there are few relatively simple and flexible models able to simulate seasonal variations in phosphorus concentrations in water bodies and particularly in reservoirs. In this study, the two-layer dynamic model, LakeMab, simulating phosphorus variations in water bodies, was enhanced to consider some tributary characteristics and reservoir specificities. It was then applied to the case of a reservoir in western France, Lake Bultière. Without any calibration, the modified model reproduced reasonably well seasonal variations in phosphorus concentration in the lake. A sensitivity analysis showed the importance of improvements related to reservoir functioning (outlet depth, water level fluctuations) and the smaller importance of those related to tributaries (variable concentrations, depth of riverine inputs). The model can easily be applied to diverse lentic systems and could be coupled to stream models, thereby making it a useful tool for managing water quality in lakes and reservoirs.
\end{abstract}

Keywords Lake $\cdot$ Dynamic model $\cdot$ Eutrophication $\cdot$ Phosphorus $\cdot$ Reservoir

Handling Edior: Haw Yen.

Electronic supplementary material The online version of this article (https://doi.org/10.1007/s10201-019-00606-x) contains supplementary material, which is available to authorized users.

Vincent Roubeix

vincent.roubeix@laposte.net

1 Pôle R\&D "ECLA", Aix-en-Provence, France

2 Irstea, Aix Marseille Univ, RECOVER, Aix-en-Provence, France

3 Margaretha Kamprad Chair, Physics of Aquatic Systems Laboratory, EPFL-ENAC-IEE-APHYS, 1015 Lausanne, Switzerland

4 Segula Technologies, L'Hospitalet de Llobregat, Barcelona, Spain

5 University of Maryland Center for Environmental Science/U.S. Environmental Protection Agency Chesapeake Bay Program, Cambridge, USA

6 Irstea, UR RiverLy, LHQ, Rue de la Doua, 69100 Villeurbanne, France

7 OFB, Aix-en-Provence, France

\section{Introduction}

From the middle of the twentieth century, the intensive use of phosphorus $(\mathrm{P})$ in detergents and as a fertilizer in agriculture dramatically increased $\mathrm{P}$ input from rural and urban areas to aquatic ecosystems (Elser and Bennett 2011; Smith 2003; Smith et al. 1999). The resulting phenomenon of cultural eutrophication is a major cause of lake ecological alterations (Cardoso et al. 2009). Indeed, $P$ is an essential and often limiting nutrient for algal growth in lakes. Its concentration in lake water stimulates primary production and the resulting accumulation of organic matter can have harmful environmental and socioeconomic impacts such as increased water turbidity, anoxia, fish kills, and loss of biodiversity. Moreover, excess $\mathrm{P}$ favors the proliferation of toxic cyanobacteria which represents an additional threat to ecosystem functioning and services (Downing et al. 2001; Paerl et al. 2011).

The importance of limiting the concentrations of $\mathrm{P}$ in lakes has been recognized for long (Schindler 1974; Vollenweider 1968). The pioneer work of Vollenweider in the early 
1970s aimed at linking $\mathrm{P}$ input from the watershed to lake concentration (Vollenweider 1975). The developed models were used to estimate the maximal P load from watershed to comply with a limit of concentration in lakes. The nutrient load depends on land use and can be modified by human activities in the watershed, while the concentration in lake water determines the impact on the ecosystem. The relationship between load and concentration is not linear and may show complex dynamics because of internal loading as a result of biogeochemical interactions between sediments and the water column (Carpenter et al. 1999; Søndergaard et al. 2003).

The evaluation of the ecological status of water bodies in the context of the European Water Framework Directive (WFD) implied the definition of P standards for lakes (European Commission 2000). According to the WFD, nutrient standards need to be related to the response of aquatic communities (fish, invertebrates, macrophytes, phytoplankton, and microphytobenthos) to eutrophication. In lakes, robust statistical relationships were established between total phosphorus (TP) concentration and phytoplankton communities which are directly influenced by nutrient availability (Carvalho et al. 2013; Phillips et al. 2008; Roubeix et al. 2016). Thus, P thresholds based on changes in phytoplankton composition and cyanobacterial abundance may be used as standards for lake management.

The evaluation of ecological status based on such standards requires a reliable knowledge of $\mathrm{P}$ concentration within lakes. National monitoring networks such as those set up for the implementation of the WFD, generally provide recent data for a large number of sites with a common sampling protocol. In France, measurements of TP concentration are available in a national database for a few hundreds of lakes, but they may not be representative of the whole water body because of limited sampling frequency and spatial coverage. Moreover, only the largest lakes $\left(>0.5 \mathrm{~km}^{2}\right)$ are considered in this survey and they represent only a small fraction of the lakes that may undergo eutrophication.

The concentration of $\mathrm{P}$ in a lake receiving surface water inflows and no significant underground input can be estimated from $\mathrm{P}$ concentration in the tributaries and from the water discharge to the lake. Water discharge can be obtained either directly from gauged hydrometric stations on the tributaries, or using a hydrological model. TP concentration in the tributaries may be derived from water quality monitoring stations and can be interpolated in time using concentration-discharge models when the sampling frequency is low (Hirsch et al. 2010; Zhang et al. 2016).

Lake models can be divided into static and dynamic types (Bryhn and Håkanson 2007). Static models assume that the lake is at steady state, i.e., the concentration of $\mathrm{P}$ is constant at the study time scale. Most of these models are based on the hypothesis that lakes are simple well-mixed reactors in which $\mathrm{P}$ enters via the tributaries and is lost through outflow and retention in the bottom sediments. These empirical models, however, generally estimate annual means of in-lake $\mathrm{P}$ concentration and do not address seasonal variations (Windolf et al. 1996).

Dynamic models use differential equations, to describe the evolution of state variables (e.g., surface $\mathrm{P}$ concentration) under the effect of forcing variables (e.g., varying $\mathrm{P}$ load from tributaries). They usually require many parameters which can be estimated through model calibration. The advantage of a dynamic model is to give insight into lake functioning and to capture seasonal to daily variations in lake $\mathrm{P}$ concentration. Such a model can be useful to assess the uncertainty associated with a standard sampling protocol when time- and space-integrated $\mathrm{P}$ concentration needs to be estimated for ecosystem evaluation. Moreover, such an integrated approach makes it possible to establish a link between management targets in lakes and their tributaries.

Among the numerous dynamic lake ecosystem models simulating P concentration (Mooij et al. 2010; Janssen et al. 2015), very few of them are general models designed for application to a wide diversity of lakes without tuning or calibration. Such models calibrated against data from a wide range of lakes are particularly useful for large-scale studies on many lakes, or for more local studies where there are little environmental data available for lake-specific calibration. LakeMab is a general P model for lakes which proved to perform quite well on an interannual basis in comparison with other static or general dynamic models such as PCLake (Bryhn and Håkanson 2007; Håkanson and Bryhn 2008; Janssen et al. 2019). Originally designed for the modelling of radioactive compounds and suspended matter (Håkanson 2000, 2006), LakeMab distinguishes between a surface and a deep layer and their corresponding sediment areas where erosion and transport (ET), or accumulation (A) take place, respectively. LakeMab was proposed as an alternative to static models owing to its flexibility. It includes a simple characterization of basin morphology based on a geometric approximation (Håkanson 2005; Johansson et al. 2007) and the required driving variables are easily accessed (Håkanson and Bryhn 2008). Nevertheless, when additional forcing data are available, they can be used for a more accurate modeling of P. A variable TP concentration in the tributaries derived from measurements and/or modeling may be used instead of a constant concentration. As lake morphometry has a large influence on lake geochemical processes (Håkanson 2005), water level fluctuations should also be taken into account, especially for reservoirs whose depth and area may vary considerably.

The aim of this study is to assess the utility of a relatively simple dynamic model such has LakeMab to describe seasonal variations in mean $\mathrm{P}$ concentrations in reservoirs. LakeMab was tested on a French reservoir (Lake Bultière, 
Vendée), using flow discharge and P concentration measurements from tributaries and a concentration-discharge model to estimate $\mathrm{P}$ inputs. Moreover, some modifications of the model were proposed to take into account variable $\mathrm{P}$ concentration and temperature in tributaries and some specific physical aspects of reservoirs, namely, outlet depth and water level fluctuations.

\section{Methods}

\section{LakeMab model}

\section{General description}

LakeMab is a process-based model that quantifies the transport of TP in lakes via inflow by tributaries, outflow, sedimentation, mixing, resuspension, diffusion and retention in sediments (Fig. 1). Its structure and equations were completely described in Håkanson and Bryhn (2008). There are four state variables in LakeMab: the mass of TP in the surface layer, in the deep layer, and in two sediment compartments associated with the water layers. The sediment compartments are the sediment where erosion and transport take place below the surface layer (ET-sediment) and where accumulation take place below the bottom layer (A-sediment).
This implies that the two water layers are separated vertically on a sedimentological basis by the theoretical wave base $\left(D_{\mathrm{wb}}\right)$. The model was created with a general description of processes so that it can be easily applied to various types of lakes. Model parameters were used without recalibration except those concerning the temperature sub-model (Ottosson and Abrahamsson 1998), simulating surface and bottom water temperatures. To improve its applicability to French lakes, the temperature sub-model was modified by Prats and Danis (2019) following the work of Kettle et al. (2004). The few parameters of the model were estimated using satellite and in situ temperature measurements for the period 1999-2016 (Prats and Danis 2019). The empirical water discharge sub-model of LakeMab (Abrahamsson and Håkanson 1998) was not used in this study because discharge data to the lake were already available. Hence, the driving variables needed to run the model in its original form were: mean TP concentration in tributary, lake area, mean depth, continentality, altitude, latitude and annual precipitation.

\section{Model developments}

Four possibilities to extend the model were tested to improve the results. The developments were relatively simple to keep the model at a low level of complexity. Nevertheless, they
Fig. 1 Structure of LakeMab and processes: a original model for lakes; $\mathbf{b}$ developments of the model for the case of a dammed reservoir. Model state variables are represented in rectangles: mass of TP in the surface layer (Psw), in the deep layer (Pdw), in the erosion-transport sediment (Pet) and in the accumulation sediment $(\mathrm{Pa})$ a
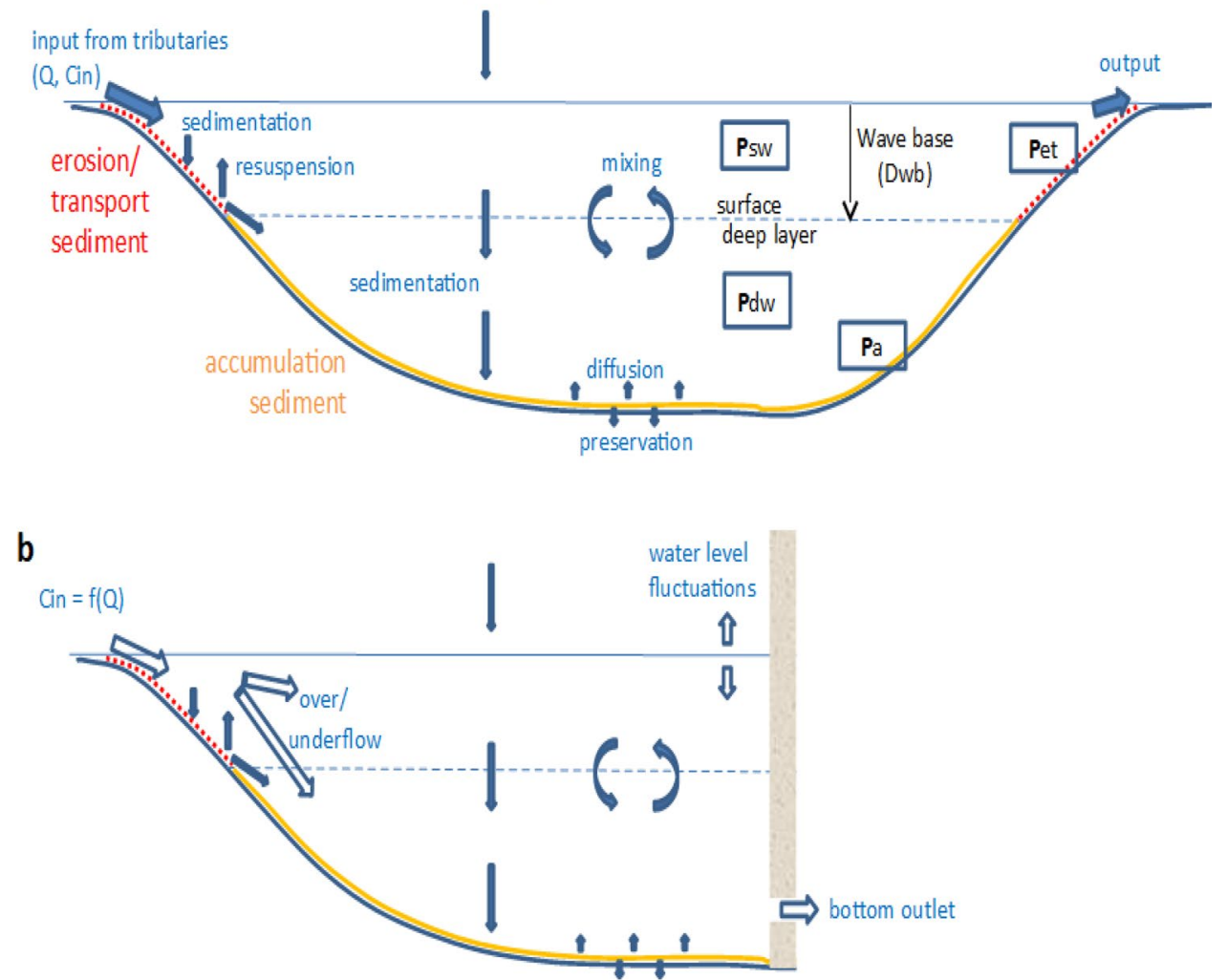
required additional data of TP concentration in tributary and lake water level. Two of these developments are related to the tributaries: the consideration of variable TP concentration in the tributaries (C-Q) (1) and the density-dependent entrainment of inflows (DDEI) (2). The two others are particularly relevant for reservoirs: the bottom outlet from the deep-water layer (BO) (3) and the consideration of water level fluctuations (WLF) (4). The second and the third are related to vertical gradients and may be meaningful for stratified lakes.

Variable TP concentration in the tributaries (C-Q) In its default setup, LakeMab uses a constant concentration of TP in the tributaries. It corresponds to a chemostatic hypothesis assuming that concentration and discharge are independent. However, the concentration of TP in the tributaries may be modulated by the discharge due to dilution or mobilization effects. A concentration-discharge model can therefore be used to calculate a more realistic TP concentration in waters entering the lake. The WRTDS model (weighted regressions on time, discharge, and season, Hirsch et al. 2010), developed to improve statistical estimation of daily concentrations and loadings based on discrete water-quality sampling for concentration, was used in this study. Like many regression-based models, the WRTDS uses time, discharge and season as explanatory variables. WRTDS model was calibrated on monthly measurements in lake tributaries and applied to derive a concentration corresponding to each discharge level (Fig. 2).

Density-dependent entrainment of inflows (DDEI) Inflow is directed in LakeMab to the surface layer of the lake. However, if the lake is stratified, the entering flux may go either to the surface or the deep layer according to water density. To improve LakeMab, a logistic model of surface water temperature (Mohseni et al. 1998) was used to estimate the temperature of the tributary water. According to this model water temperature $T_{\mathrm{w}}$ is calculated as

$T_{\mathrm{w}}=\mu+\frac{\alpha-\mu}{1+\mathrm{e}^{\gamma\left(\beta-T_{\mathrm{a}}\right)}}$,

where $T_{\mathrm{a}}$ is air temperature and $\alpha, \beta, \gamma$ and $\mu$ are calibration parameters. These parameters were calibrated for metropolitan France using data of the French national temperature monitoring network (Prats Rodríguez and Danis 2017) giving $\alpha=20.86{ }^{\circ} \mathrm{C}, \gamma=0.1968{ }^{\circ} \mathrm{C}^{-1}, \mu=3.512{ }^{\circ} \mathrm{C}$ and,

$\beta=12.71-0.0045 \cdot$ altitude

where altitude is in meters. Water density was estimated from modelled temperature using the equation of Markofsky and Harleman (1971). The inflow was directed in the model towards the water layer having the closest density.

Bottom outlet (BO) The outflow of surface water from the lake surface layer, as is implemented in LakeMab, may not be appropriate for reservoirs. Indeed, in many cases, water is released from a valve located at the bottom of the dam. It is a simple change in the model to make water exit from the bottom, but it can have a great influence on overall lake water quality (Marcé et al. 2010; Prats et al. 2018). When the input from tributaries was directed to the surface layer, the excess of water in the surface layer was transferred to the deep layer (ESM 1).

Water level fluctuations (WLF) In a reservoir, water level fluctuations (WLF) may be large and frequent. Changes in water volume in a reservoir have a direct effect on nutrient concentration. LakeMab does not explicitly account for lake level fluctuations but it can be modified to simulate TP concentration in varying water level conditions. At each time step of simulation, the volume, surface and depth parameters are re-estimated using the hypsometric relation-
Fig. 2 TP concentration in the tributaries estimated by the WRTDS model: variations simulated for the period 2006-2015 from daily discharge data (left) and relationship to discharge over the same period (right). The points indicate the measurements made at the hydrometric station
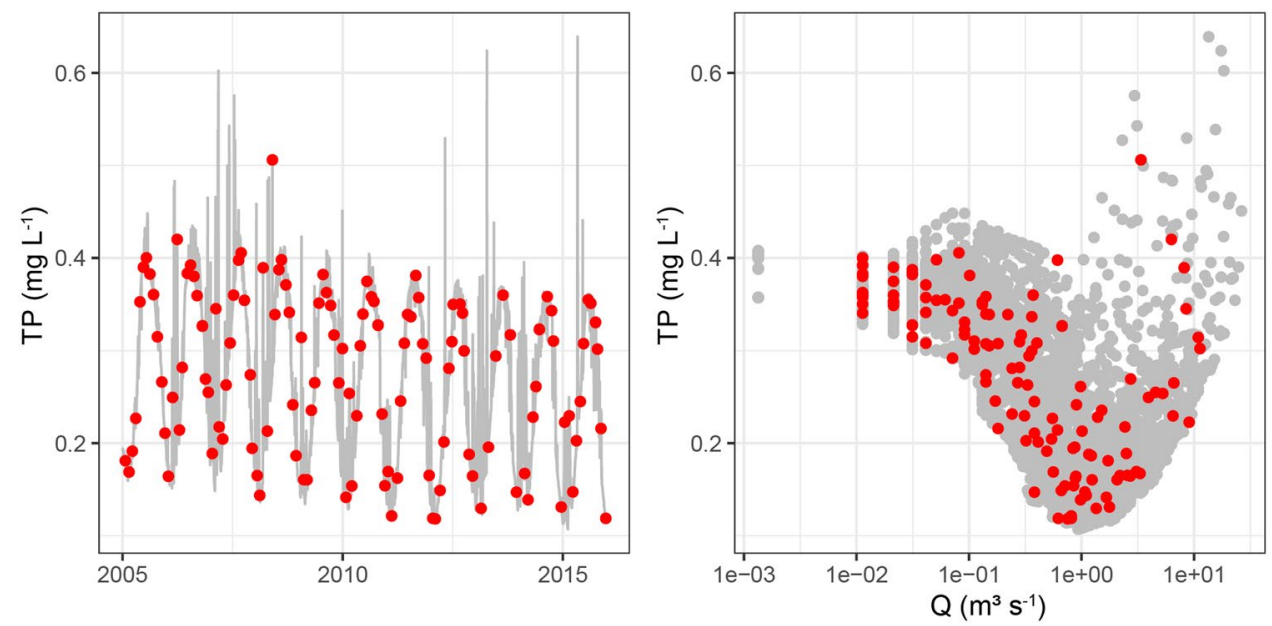
ships proposed by Johansson et al. (2007). The $H_{\mathrm{d}}$ approach assumes that the volume of a lake can be assimilated to a pile of disks whose centers are on a same vertical line and whose radius decrease with depth following an exponential function. The hypsometric parameter $H_{\mathrm{d}}$ determines the slope and the convexity of the lake basin. Its values have been determined for a set of Swedish lakes according to the volume development parameter $\left(V_{\mathrm{d}}\right)$ which measures how much the volume of a lake differs from the volume of a cone with the same area and depth. The $H_{\mathrm{d}}$ approach was shown to work well on a set of French lakes with known bathymetry (Prats Rodríguez and Danis 2017).

Changes in the surface area modify the depth of the wave base $\left(D_{\mathrm{wb}}\right)$ and the surface of the sediment compartments. This results in a transfer of TP between water layers and sediment compartments and in a loss of sediment $P$ near the shoreline when the water level drops. The transfers of TP induced in the model by WLF are described in detail in the electronic-only material (ESM 1).

\section{Time resolution}

LakeMab was designed to be used at monthly or weekly time resolution (Håkanson and Boulion 2002; Håkanson and Bryhn 2008). For the case of Lake Bultière, daily time series were available for discharge and WLF. Thus, these data were first averaged monthly for simulations at the monthly time scale. In a second step, daily data were directly used in the model to assess the consequences for the simulations of a higher time resolution of input data.

\section{Model implementation}

LakeMab was implemented with R (R Core Team 2018) using the package 'deSolve' (Soetaert et al. 2010). Simulations were performed using the LSODA integration method at a time step of 0.01 month, continuously from 2006 to 2015. The R script of the extended version of LakeMab model is available in the Electronic Supplementary Material (ESM 2). The model was run with all the developments proposed at monthly and daily time scales, and finally, each development was withdrawn separately to assess its effect on the simulation. The basic configuration of the model is an inflow with a constant TP concentration estimated by the WRTDS approach (mean on the simulation period) and entering the reservoir into the surface layer, a constant water level (mean of measured maximal depth) and an outflow from the surface layer.

\section{Study area}

The extended LakeMab model was tested on a reservoir to assess its capacity to simulate variations in mean TP concentration over a decade. Lake Bultière was chosen from a national lake database because it is quite typical for West France reservoirs and because all data concerning the lake and its tributaries were available to run the model.

\section{Lake and tributaries description}

Lake Bultière is located in the Vendée region, Western France $\left(46^{\circ} 55^{\prime} 05^{\prime \prime} \mathrm{N}, 1^{\circ} 12^{\prime} 30^{\prime \prime} \mathrm{W}\right)$ (Fig. 3). It was created in 1994 on the Grande Maine River. It has a surface area of $0.6 \mathrm{~km}^{2}$, a mean depth of $8.5 \mathrm{~m}$, and a catchment area of $159 \mathrm{~km}^{2}$. It receives a mean discharge of $1.5 \mathrm{~m}^{3}$ $\mathrm{s}^{-1}$, mostly from the Grande Maine River, with maximum values reached during winter. The catchment is characterized by a large proportion of intensive agriculture (70\%) and a moderate urbanization level (7\%). The water level of the reservoir drops considerably at the end of summer and the mean annual amplitude of its fluctuations is about $4 \mathrm{~m}$. The reservoir has a poor water quality because of high nutrient concentrations. The national lake phytoplankton index (Laplace-Treyture and Feret 2016) indicated a poor ecological status in 2007 and 2010 and cyanobacterial blooms are often observed.

\section{Environmental data}

Daily water discharge and TP concentration in the tributaries were obtained from a gauging and water quality station representing $83 \%$ of the lake catchment area. The total water discharge to the lake was estimated by extrapolating the discharge:surface ratio to the remaining part of the watershed. Mean annual precipitation data were provided by the SAFRAN meteorological model (Système d'Analyse Fournissant des Renseignements Adaptés à la Nivologie, Vidal et al. 2010). Some measurements of TP concentration were completed in the lake in the framework of a national survey. The common protocol used in the lake network was an integrated sample over the euphotic zone (estimated as $2.5 \times$ Secchi disk depth, 1-4 m) and another sample at the bottom ( $1 \mathrm{~m}$ above sediment), at only one station located above the deepest point of the lake ( $\left.46^{\circ} 55^{\prime} 4.09^{\prime \prime} \mathrm{N}, 1^{\circ} 12^{\prime} 45.38^{\prime \prime} \mathrm{W}\right)$ and four times a year. Samples were collected in three years of the simulation period $(2007,2010$, and 2013). These measurements were compared with lake mean concentrations simulated by the model, after calculation of the TP concentration in the euphotic zone from simulated surface and deep-water concentration and the measured photic depth. The RMSE was used to assess model fit to the 24 data points. 
Fig. 3 Environmental characteristics of Lake Bultière: a map of the lake catchment with its tributaries (sources: BD ALTI®-IGN, INSEE) and location of the hydrometric station (triangle); b map of Lake Bultière and location of the sampling site (circle) near the dam

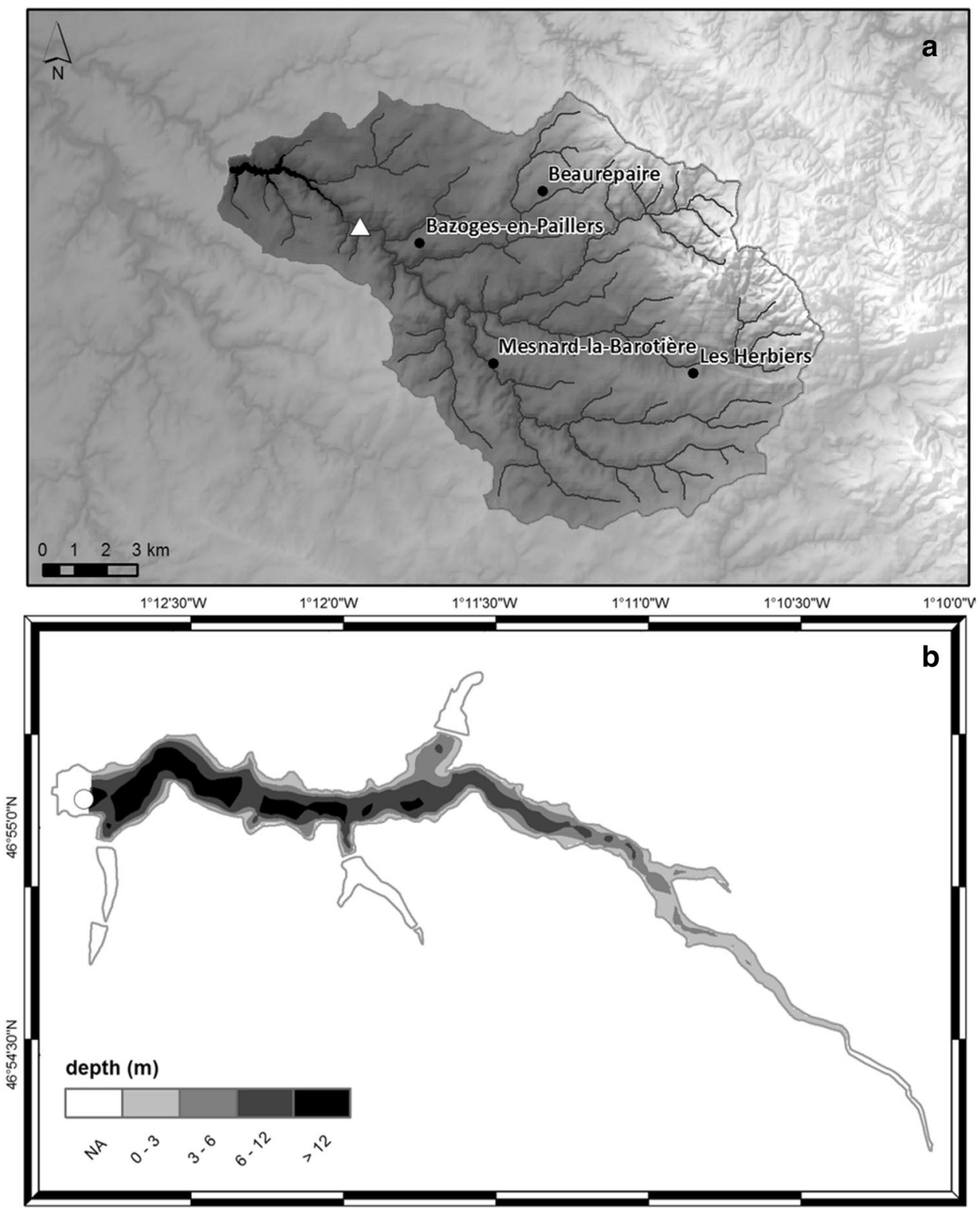

\section{Results}

In the decade 2006-2015, TP concentration in the tributaries was highest during the summer and lowest during the winter floods (Figs. 4 and 5). The amplitude of water level fluctuations of the reservoir has decreased significantly since 2012 with a maximum depth remaining above $14 \mathrm{~m}$ at the end of the summer. Surface and bottom water temperatures of the reservoir were generally very close during the winter, but surface water became significantly warmer than bottom water temperatures during the summer, corresponding to a seasonal thermal stratification of the reservoir. The temperatures measured at the sampling station were quite close to the values simulated by the model. However, there was a slight overestimation of bottom water temperature at summer sampling dates in 2010 and 2013. In addition, for the last sampling in 2007, the surface and bottom water simulated temperatures were still quite different on a monthly time scale, while the measurements were almost equal, reflecting the vertical mixing of the reservoir. The simulated temperature in the tributaries was closer to the lake surface temperature in winter and to deep water temperature in summer. In the model, this resulted in the direction of riverine inflow towards the surface layer in winter and towards the deep layer in summer.

The TP concentration at the bottom was much higher than that of the surface (Figs. 4, 5). Concentrations in both layers became nearly equal during winter mixing. The depth of the wave base separating the two layers remained low during the simulations $\left(1.1 \mathrm{~m}<D_{\mathrm{wb}}<1.5 \mathrm{~m}\right)$, which is why 
Fig. 4 Simulation with the extended model at monthly time resolution. Variables shown are: a TP concentration in the reservoir, in the surface and deep layer; $\mathbf{b}$ TP concentration in the tributaries (Cin) and water discharge from tributaries $(\mathrm{Q})$; c water temperature in the surface and deep layers and in the tributaries; and $\mathbf{d}$ maximal depth of the reservoir, indicating water level fluctuations

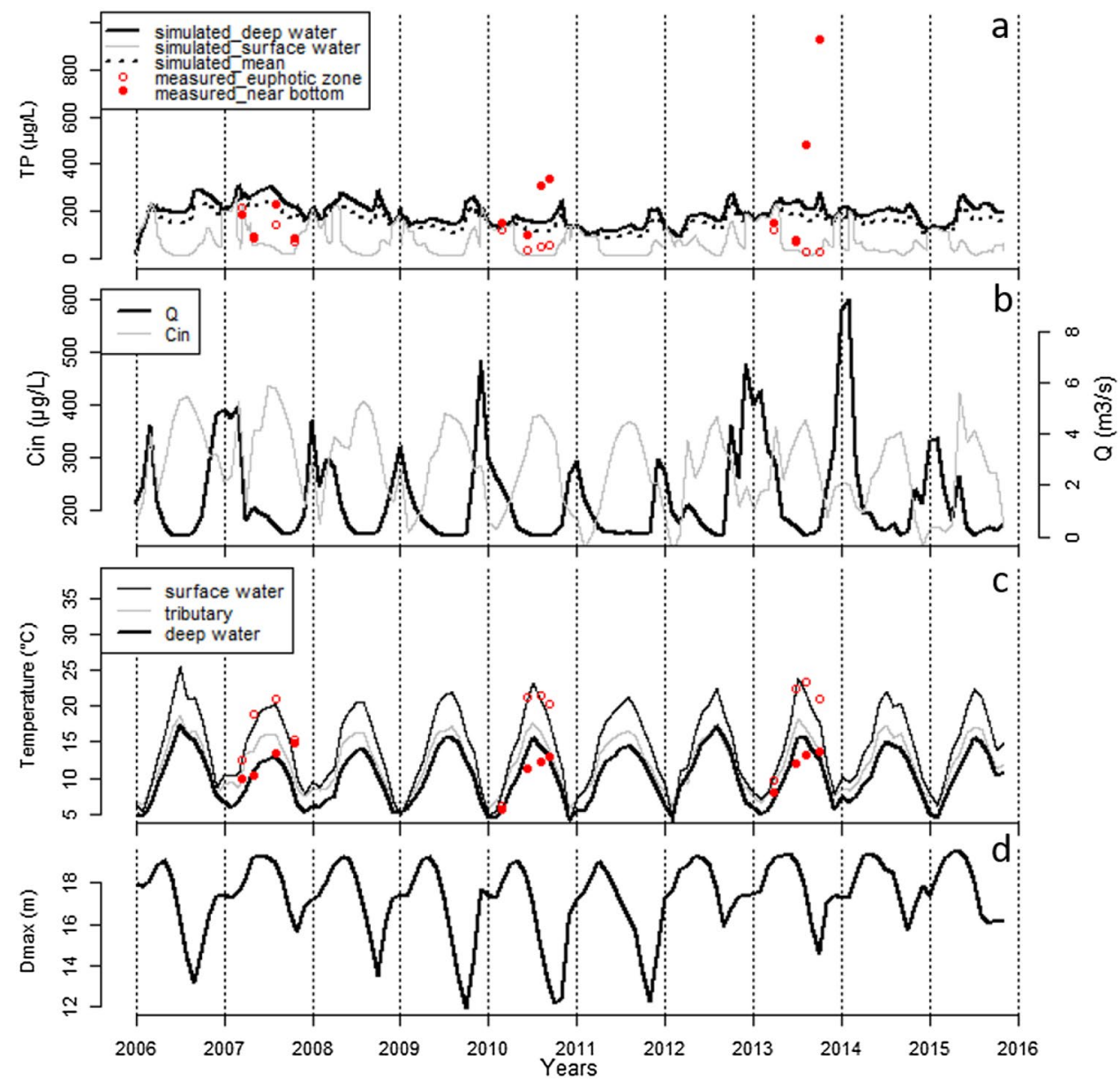

the average concentration in the water column was close to bottom water concentration during the simulation period. Surface TP concentration reached a minimum during summer. Mixing during winter caused TP surface concentration to rise. Variations in TP concentration at the bottom were characterized by an initial increase at the beginning of the year following significant inputs during winter floods, and by a peak due to the drop in water level and the consecutive refilling of the reservoir at the end of the year. Daily simulations produced higher temporal variability (especially at the surface) due to the high variability of discharge and TP concentrations in the tributaries. The effect of the drop in water level on bottom TP concentration was more pronounced at daily resolution (Fig. 5).

Simulated TP concentrations were generally similar to in situ measurements, but there were significant differences at several dates that can be separated into two types: (1) differences between surface and deep values and (2) deviations in deep values. For the first type, the simulated surface and deep concentrations were different while the measurements were similar and at the level of simulated surface values. These differences were observed in spring 2007 and 2013 and in late 2007.
The other type of large differences between simulated and measured values could be observed at the end of 2010 and 2013, at the monthly resolution (Fig. 4). In both years, the measured bottom values were well above the simulated values, around $200 \mu \mathrm{g} \mathrm{L}^{-1}$. The highest values were reached at the end of 2013, with nearly $1 \mathrm{mg} \mathrm{P} \mathrm{L}^{-1}$ during the last campaign. At the daily resolution, the simulated peak concentration of TP at the bottom matched the measurements in 2010 better, and approached them in 2013, although large differences (100-500 $\left.\mu \mathrm{g} \mathrm{L}^{-1}\right)$ remained.

These high deviations, especially in 2013, result in a

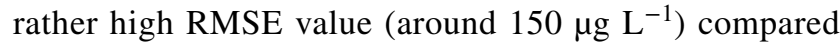
to the average of the concentration values over the period (Fig. 6). The various improvements made to the LakeMab model were evaluated by the sequential withdrawal of each of them and the resulting increase in RMSE (Fig. 6). Thus, variations in TP concentration in tributaries as a function of discharge on the one hand and the depth of water entrainment in tributaries as a function of temperature on the other hand, appeared to be of little importance for modelling TP in Lake Bultière, at daily resolution at least. On the contrary, taking into account WLF and especially the outflow of water from the bottom of the reservoir considerably improved the 
Fig. 5 Simulation with the extended model at daily time resolution. Same variables as in Fig. 4
Fig. 6 RMSE for simulations at monthly and daily time resolution with the extended LakeMab model and without each of the four developments considered in this study $(C-Q$ varying

TP concentration in tributaries related to discharge, $D D E I$ density-dependent entrainment of inflows, $W L F$ water level fluctuations, $B O$ bottom outlet)
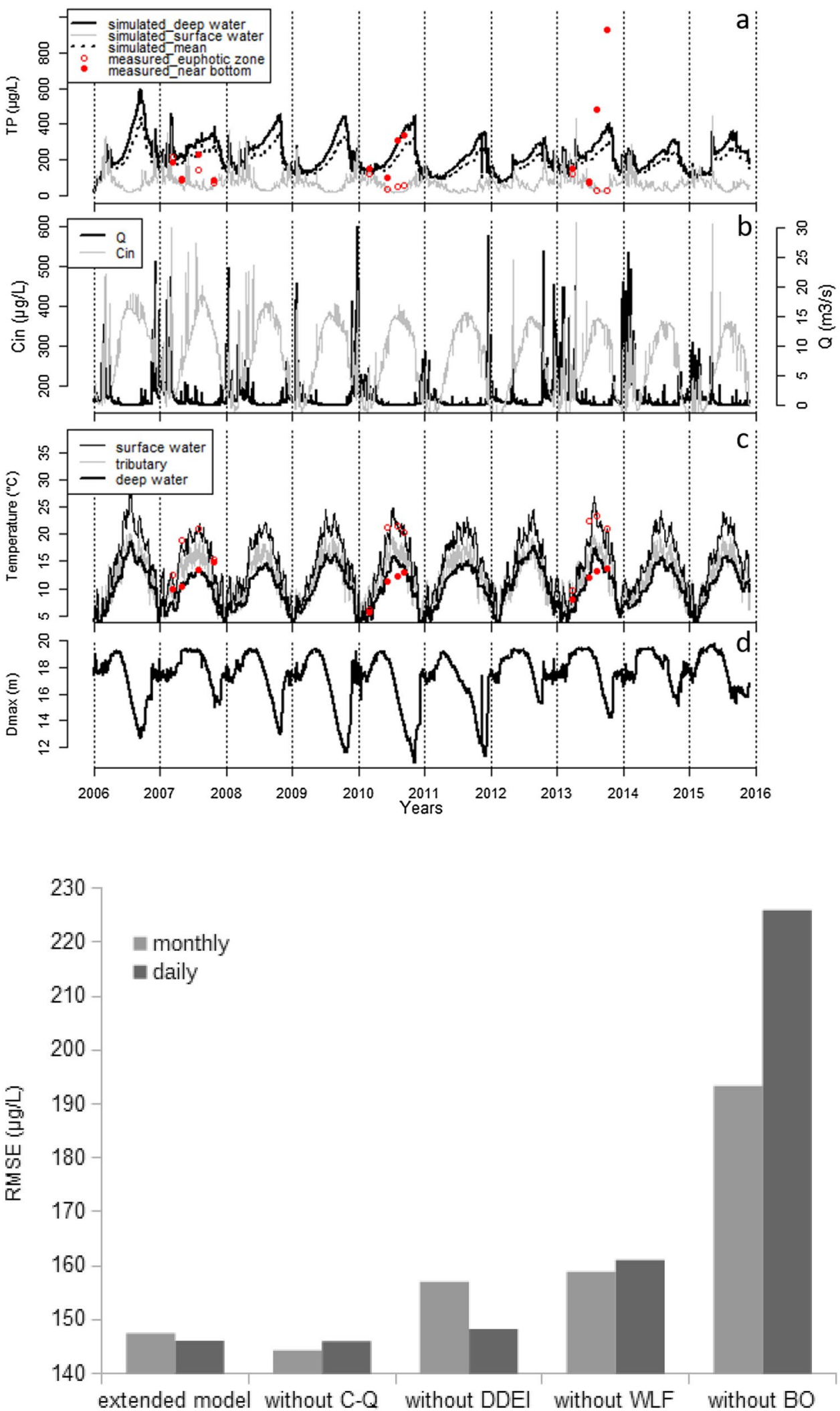
simulations. The model was very sensitive to the position of the outlet depth.

\section{Discussion}

The modified version of the LakeMab model simulated variations in the mean TP concentration in a reservoir on a monthly or daily time scale. The concentrations simulated in Lake Bultière over the period 2006-2015 were consistent in their average level and dynamics with the measurements made in the water body. However, there were significant differences on several dates. The discrepancy between measured and simulated values may be explained by measurement uncertainty, extreme weather conditions or model failure which could justify some improvements.

While the sampling station located at the deepest point near the dam is considered representative of the water body, the upstream-downstream spatial heterogeneity of this type of elongated reservoir may explain some of the differences between the measurements and the simulated mean values for the entire water body. Indeed, the chemical composition of the water follows a gradient from the tail to the dam, wherein the concentration of nutrients tends to decrease as water flows through the reservoir and suspended TP sinks (Armengol et al. 1999). In addition, surface measurements correspond to the euphotic zone whose depth generally exceeds the boundary between the two layers in the model $\left(D_{\mathrm{wb}}\right)$, which may explain why surface measurements are slightly higher than the simulated values (Figs. 4, 5).

The comparison of simulations at monthly and daily resolution shows the advantage of using daily frequency data with regard to the effect of WLF, although RMSE did not vary much between simulations. The gradual variations in water level result in a limited effect of data frequency on the associated water flows. On the other hand, the use of monthly discharge data artificially increased the duration of winter floods that were concentrated in time. The early increase in discharge with low TP concentration counterbalances the concentration effect linked to the drop in water level, which limits the increase in TP at the end of the year at monthly resolution. The same effect was visible at daily resolution in 2012, when a longer duration of winter floods reduced the TP peak associated with WLF.

Considering the simulations at daily resolution, there were, at several campaigns, differences between the simulated deep and surface TP concentrations while the measurements between the two depths were very close. These differences could be explained by a poor representation in the model of the stratification/mixing cycles of the water body. The model seemed to overestimate the stratification period. However, the simulated temperatures matched the measurements quite well (Figs. 4, 5). The second campaign of each year was characterized by (1) very different temperature values between the surface and the bottom water and (2) measured TP concentrations that were still very close, unlike the simulated values. Thermal stratification could be correctly modelled, but chemical stratification was anticipated. This could be due to an overestimation of TP sedimentation from surface to deep water.

The surge in TP concentrations at the end of 2013 suggests the effect of a higher amplitude of WLF. However, the drop in reservoir level was no greater than in other years. Deep water anoxia stimulating P release from sediment could also be an explanation, but similar low $\mathrm{O}_{2}$ levels were recorded in the other sampled years (Fig. S1). The previous winter was marked by an exceptionally long flood period (Figs. 4b, 5b) and there could have been an accumulation of TP in the sediments that was released at the end of the year. The examination of simulated TP in sediments showed an accumulation between winter 2012 and spring 2013, producing a relatively large stock over the study period (Fig. 7). The release of the excess TP by diffusion in the model was not sufficient to generate concentrations at the level of those measured.

The use of a concentration-discharge model made possible the estimation of the average annual TP concentration in the tributaries, based on the sparse measurements available in the watershed. This estimate is necessary to perform simulations with the basic LakeMab model (Håkanson and Bryhn 2008). The inclusion in the model of the variability of concentration in tributaries by linking it to discharge did not improve the simulations (Fig. 6). This result is surprising given the magnitude of variations in concentrations in
Fig. 7 Simulated TP in Accumulation sediments over the period of study, showing $\mathrm{P}$ accumulation over the year 2012 (daily time scale)

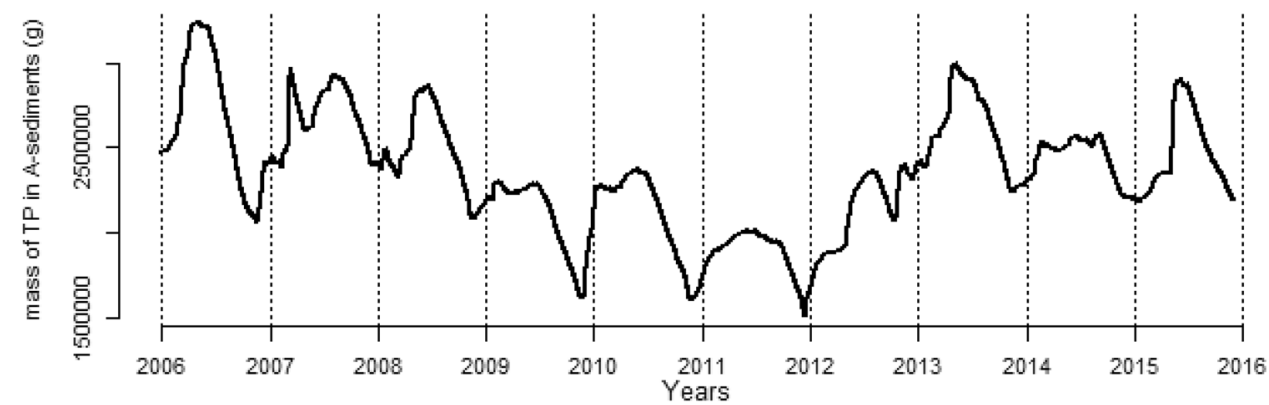


tributaries. But what matters for the non-spatialized model is the input of TP. In fact, during most of the year, the TP concentration was negatively correlated to discharge, i.e. a dilution effect (Figs. 2, 4), which limited the intra-annual input variations by a compensating effect. The highest effect of C-Q can be seen during the flood periods above $1 \mathrm{~m}^{3} / \mathrm{s}$ when TP concentration in tributaries increased with discharge (Fig. 2). The floods generated a pulse of TP input to the lake which had an impact on lake concentration, as can be seen at the beginning of 2007 (Figs. 4, 5). The gain of the C-Q development of the model would probably appear more clearly if more measurements had been done across a wider range of hydrological conditions. It may also vary with C-Q modalities among lakes. A study of nearly 300 watersheds identified three C-Q modalities for TP: (1) a concentration that is indifferent to discharge ( $24 \%$ of cases), (2) a concentration that decreases with discharge up to a threshold above which it no longer varies (23\%) and (3) a concentration that is indifferent to discharge up to a threshold above which it increases with discharge (29\%) (Moatar et al. 2017). The WRTDS model used in this study can represent complex $\mathrm{C}-\mathrm{Q}$ relationships and properly capture the variations in TP concentration over the simulation period (Hirsch et al. 2010; Zhang et al. 2016; Zhang 2018).

Considering the temperature of the tributaries, the effect of the DDEI was to direct inputs from the tributaries to the surface layer during winter and to the bottom layer during summer. The consequences for the simulations are the homogenization of the two layers during the winter and a significant decrease in TP concentration in the surface layer during the summer stratification period (Fig. 4). The improvement in simulations is very low considering the RMSE, especially at daily resolution (Fig. 6), but the DDEI represents a relatively simple development to implement that allows a better representation of the effects of seasonal stratification on TP concentrations. It could play a larger role on lakes with more pronounced stratification. In addition, the consideration of the water entrainment depth is consistent with that of the water outlet depth, which corresponds to another important development of the model.

The seasonal decrease in water level had an important effect on TP concentration, as shown by the sensitivity analysis of the model (Fig. 6). It produced a peak in TP concentration in the bottom water layer in autumn (Fig. 5). The influence of WLF can be assessed during 2007, which is marked by a later and less pronounced drop in level than in other years and therefore a lower peak of TP. The implementation of WLF in the model is more complicated than the other proposed developments, because each variation in water level requires an adjustment of the model structure, including the thickness and volume of the layers and the surfaces of the two sediment compartments (ESM 1). These structural adjustments imply TP transfers between the compartments of the model. Thus, for example, during a drop in level, some of the accumulation sediments become erosion-transport sediments that can be resuspended in the surface layer. This results in an increase in TP concentration in the surface layer, which can be seen at monthly resolution (Fig. 4). Another consequence is the increase in surface turbidity that can reduce primary production and impact reservoir trophic functioning, as discussed by Håkanson (2005) for Lake Kinneret and as part of the application of the LakeWeb model (Håkanson and Boulion 2002), an extension of LakeMab to the lake food web.

The outlet depth appeared to be an essential parameter for reservoir modeling. The surface water outlet from the surface, as assumed in LakeMab, was not suitable for Lake Bultière. Indeed, the dam is equipped with a bottom valve through which water is released. When the water was extracted from the deep layer, the error produced by the model was much reduced (50-80 $\mu \mathrm{g} \mathrm{L}^{-1}$ lower RMSE, Fig. 6). The water extraction depth varies with WLF and the water layer involved in the model depends on the difference between the altitude of the valve and that of the wave base. In addition, some reservoirs use several valves at different heights to alternate water extraction depths. This is a method of managing the water quality in reservoirs and downstream rivers, acting on temperature, nutrient concentration and cyanobacteria blooms (Lehman et al. 2009; Palau 2006; Weber et al. 2017).

\section{Conclusions}

The extended LakeMab model can be a useful tool for the management of eutrophication in lakes and reservoirs. It allows modelling of mean TP concentration at the surface and at the bottom and at a monthly or daily time scale. The data required to carry out simulations are accessible and not numerous, and this enables its application to a large number of different water bodies, including reservoirs with the developments proposed in this study. The complexity of the model can also be adapted according to data availability. The model can simply be used to estimate the average TP concentration in a water body for the assessment of its ecological status. It can also be used to determine the TP concentration targets in tributaries to comply with an environmental quality threshold in the receiving environment. Knowledge of these variations can guide the management of dams, to preserve water quality in a reservoir and limit cyanobacterial blooms.

Acknowledgements This research was funded by Agence Française pour la Biodiversité. The authors are grateful to Vendée Eau for useful information about Lake Bultière. 


\section{References}

Abrahamsson O, Håkanson L (1998) Modelling seasonal flow variability of European rivers. Ecol Model 114:49-58

Armengol J, Garcia JC, Comerma M, Romero M, Dolz J, Roura M, Han B-H, Vidal A, Šimek K (1999) Longitudinal processes in canyon type reservoirs: the case of Sau (N. E. Spain). In: Tundisi JG, Straškraba M (eds) Theoretical reservoir ecology and its applications. Brazilian Academy of Sciences and Backhuys Publishers, Saõ Carlos, pp 313-345

Bryhn AC, Håkanson L (2007) A comparison of predictive phosphorus load-concentration models for lakes. Ecosystems 10:1084-1099

Cardoso AC, Free G, Nõges P, Kaste $\emptyset$, Poikane S, Solheim AL (2009) Lake management, criteria. In: Likens GE (ed) Encyclopedia of inland waters. Oxford, pp 310-331. https://doi. org/10.1016/B978-012370626-3.00244-1

Carpenter SR, Ludwig D, Brock WA (1999) Management of eutrophication for lakes subject to potentially irreversible change. Ecol Appl 9:751-771

Carvalho L, Poikane S, Solheim AL, Phillips G, Borics G, Catalan J, De Hoyos C, Drakare S, Dudley BJ, Jarvinen M, LaplaceTreyture C, Maileht K, McDonald C, Mischke U, Moe J, Morabito G, Noges P, Noges T, Ott I, Pasztaleniec A, Skjelbred B, Thackeray SJ (2013) Strength and uncertainty of phytoplankton metrics for assessing eutrophication impacts in lakes. Hydrobiologia 704:127-140

Downing JA, Watson SB, McCauley E (2001) Predicting cyanobacteria dominance in lakes. Can J Fish Aquat Sci 58:1905-1908

Elser J, Bennett E (2011) A broken biogeochemical cycle. Nature 478:29

European Commission (2000) Directive 2000/60/EC of the European Parliament and of the Council of 23 October 2000 establishing a framework for community action in the field of water policy. The European Parliament and Council, p 72

Håkanson L (2005) The importance of lake morphometry for the structure and function of lakes. Int Rev Hydrobiol 90:433-461

Håkanson L (2000) Modelling radiocesium in lakes and coastal areas- new approaches for ecosystem modellers. A textbook with Internet support. Kluwer, Dordrecht

Håkanson L (2006) Suspended particulate matter in lakes, rivers and marine systems. Blackburn, New Jersey

Håkanson L, Boulion V (2002) The Lake Foodweb: modelling predation and abiotic/biotic interactions. Backhuys Publishers, Leiden

Håkanson L, Bryhn AC (2008) A dynamic mass-balance model for phosphorus in lakes with a focus on criteria for applicability and boundary conditions. Water Air Soil Pollut 187:119-147

Hirsch RM, Moyer DL, Archfield SA (2010) Weighted regressions on time, discharge, and season (WRTDS), with an application to Chesapeake Bay River Inputs. J Am Water Resour Assoc 46:857-880

Janssen ABG, Arhonditsis GB, Beusen A, Bolding K, Bruce L, Bruggeman J, Couture R-M et al (2015) Exploring, exploiting and evolving diversity of aquatic ecosystem models: a community perspective. Aquat Ecol 49:513-548

Janssen ABG, Teurlincx S, Beusen AHW, Huijbregts MAJ, Rost J, Schipper AM, Seelen LMS et al (2019) PCLake+: A processbased ecological model to assess the trophic state of stratified and non-stratified freshwater lakes worldwide. Ecol Model 396:23-32

Johansson H, Brolin AA, Håkanson L (2007) New approaches to the modelling of lake basin morphometry. Environ Model Assess 12:213-228

Kettle H, Thompson R, Anderson NJ, Livingstone DM (2004) Empirical modeling of summer lake surface temperatures in southwest Greenland. Limnol Oceanogr 49:271-282
Laplace-Treyture C, Feret T (2016) Performance of the Phytoplankton Index for Lakes (IPLAC): a multimetric phytoplankton index to assess the ecological status of water bodies in France. Ecol Indic 69:686-698

Lehman EM, McDonald KE, Lehman JT (2009) Whole lake selective withdrawal experiment to control harmful cyanobacteria in an urban impoundment. Water Res 43:1187-1198

Marcé R, Moreno-Ostos E, García-Barcina JM, Armengol J (2010) Tailoring dam structures to water quality predictions in new reservoir projects: Assisting decision-making using numerical modeling. J Environ Manage 91:1255-1267

Markofsky M, Harleman DRF (1971) A predictive model for thermal stratification and water quality in reservoirs. M.I.T, Hydrodynamics Laboratory, Boston

Moatar F, Abbott BW, Minaudo C, Curie F, Pinay G (2017) Elemental properties, hydrology, and biology interact to shape concentration-discharge curves for carbon, nutrients, sediment, and major ions. Water Resour Res 53:1270-1287

Mohseni O, Stefan HG, Erickson TR (1998) A nonlinear regression model for weekly stream temperatures. Water Resour Res 34:2685-2692

Mooij WM, Trolle D, Jeppesen E, Arhonditsis G, Belolipetsky PV, Chitamwebwa DBR, Degermendzhy AG et al (2010) Challenges and opportunities for integrating lake ecosystem modelling approaches. Aquat Ecol 44:633-667

Ottosson F, Abrahamsson O (1998) Presentation and analysis of a model simulating epilimnetic and hypolimnetic temperatures in lakes. Ecol Model 110:233-253

Paerl HW, Hall NS, Calandrino ES (2011) Controlling harmful cyanobacterial blooms in a world experiencing anthropogenic and climatic-induced change. Sci Total Environ 409:1739-1745

Palau A (2006) Integrated environmental management of current reservoirs and regulated rivers. Limnetica 25:287-302

Phillips G, Pietilainen OP, Carvalho L, Solimini A, Solheim AL, Cardoso AC (2008) Chlorophyll-nutrient relationships of different lake types using a large European dataset. Aquat Ecol 42:213-226

Prats J, Danis P-A (2019) An epilimnion and hypolimnion temperature model based on air temperature and lake characteristics. Knowl Manag Aquat Ecosyst 420:8

Prats J, Salencon MJ, Gant M, Danis P-A (2018) Simulation of the hydrodynamic behaviour of a Mediterranean reservoir under different climate change and management scenarios. J Limnol 77:62-81

Prats Rodríguez J, Danis P-A (2017) Epi- and hypolimnion temperature evolution in lakes belonging to the national WFD network (Évolutions des températures de l'épilimnion et de l'hypolimnion des plans d'eau DCE nationaux). Agence Française pour la biodiversité, Aix-en-Provence

Roubeix V, Danis P-A, Feret T, Baudoin J-M (2016) Identification of ecological thresholds from variations in phytoplankton communities among lakes: contribution to the definition of environmental standards. Environ Monit Assess 188:246

R Core Team (2018) R: A language and environment for statistical computing. R Foundation for Statistical Computing, Vienna. https://www.R-project.org/

Schindler DW (1974) Eutrophication and recovery in experimental lakes: implications for Lake Management. Science 184:897-899

Smith VH (2003) Eutrophication of freshwater and coastal marine ecosystems a global problem. Environ Sci Pollut Res Int $10: 126-139$

Smith VH, Tilman GD, Nekola JC (1999) Eutrophication: impacts of excess nutrient inputs on freshwater, marine, and terrestrial ecosystems. Environ Pollut 100:179-196

Soetaert K, Petzoldt T, Woodrow Setzer R (2010) Solving differential equations in R: package deSolve. J Stat Softw 33:1-25 
Søndergaard M, Jensen JP, Jeppesen E (2003) Role of sediment and internal loading of phosphorus in shallow lakes. Hydrobiol 506:135-145

Vidal JP, Martin E, Franchisteguy L, Baillon M, Soubeyroux JM (2010) A 50-year high-resolution atmospheric reanalysis over France with the Safran system. Int J Climatol 30:1627-1644

Vollenweider RA (1968) The scientific basis oflake eutrophication, with particular reference to phosphorus and nitrogen as eutrophication factors Water management research. OECD, Paris

Vollenweider RA (1975) Input-output models-with special reference to the phoshorus loading concept in limnology. Schweiz Z Hydrol 37:53-84

Weber M, Rinke K, Hipsey MR, Boehrer B (2017) Optimizing withdrawal from drinking water reservoirs to reduce downstream temperature pollution and reservoir hypoxia. J Environ Manage 197:96-105

Windolf J, Jeppesen E, Jensen JP, Kristensen P (1996) Modelling of seasonal variation in nitrogen retention and in-lake concentration: a four-year mass balance study in 16 shallow Danish lakes. Biogeochemistry 33:25-44

Zhang Q (2018) Synthesis of nutrient and sediment export patterns in the Chesapeake Bay watershed: complex and non-stationary concentration-discharge relationships. Sci Total Environ 618:1268-1283

Zhang Q, Harman CJ, Ball WP (2016) An improved method for interpretation of riverine concentration-discharge relationships indicates long-term shifts in reservoir sediment trapping. Geophys Res Lett 43:10215-10224

Publisher's Note Springer Nature remains neutral with regard to jurisdictional claims in published maps and institutional affiliations. 